\title{
EDITORIAL
}

\section{Foreword by President of INAE}

\author{
Sanak Mishra ${ }^{1}$
}

Published online: 18 July 2020

(C) Indian National Academy of Engineering 2020

World Health Organization announced a public health emergency of International concern on 30th January 2020 arising from SARS-CoV-2 virus as COVID-19. Since then, this disease has been spreading globally at an alarming rate leading to many deaths and causing numerous hardships to human lives. To arrest the spread of COVID-19, its identification, in-term treatment, and vaccine development assume a greater significance. As a part of containment of COVID19 , Indian scientists are actively engaged in multiple aspects of disease control, and developing several engineering and technological solutions. The Indian National Academy of Engineering (INAE) is proud to present the Special Issue (SI) of the Transactions of INAE on 'Technologies for Fighting COVID-19'. The idea of the SI is that there are several technologies available in India that can easily be tweaked to address the COVID-19 pandemic. The journal provides a platform for collating such technologies, which should help bring inventors and translators/industries together.

I am happy to note that in response to the call for the SI, Transactions of INAE received a large number of submissions, out of which 49 papers are published after rigorous review process. Majority of the papers were submitted by young engineers and technologists engaged in academia, research and development, design and manufacturing industries. It is heartening to see that several technologists, scientists, and practicing engineers in India have been able to respond quickly and provide meaningful engineering and technological solutions to fight the ongoing pandemic in several frontier areas relevant to COVID-19. The SI has succeeded in a short span of 10 weeks in collating information on high technology readiness for numerous gadgets necessary for identification and effectively tackling COVID-19.
Many of the technologies reported in SI are ready for commercial exploitation.

I am sure that the information provided in the SI articles would serve as a seed for development of further ideas and technologies, and also extremely happy to inform you that all the articles published "Online First" attracted wide readership as evidenced by large number of accesses, downloads, and instantaneous citations. Modeling of COVID-19 spread has received a special attention. I could foresee a greater opportunity for scientists, engineers, and technologists to interact with industries to explore the commercialization of ready-to-use technologies described in the SI.

I am thankful to the authors for their contributions, and reviewers for sparing their valuable time and providing very critical assessments which helped in raising the standard of the articles in SI. I am also thankful to Prof. K. Bhanu Sankara Rao, Editor-in-Chief, Transactions of INAE and the Guest Editors, Prof. Amit Agrawal and Prof. Shiv Govind Singh of this SI, for conceptualizing and bringing it in a record time in spite of the difficulties and disruptions faced during lockdown period. Special thanks to Springer Nature team for first agreeing to bring out this SI, and subsequently rendering excellent cooperation throughout the reviewing, editing, and publishing stages. I hope that the readers find the articles to have high scientific content, engineering, and technological relevance to fight COVID-19 pandemic.

Publisher's Note Springer Nature remains neutral with regard to jurisdictional claims in published maps and institutional affiliations.
Sanak Mishra

president.inae@inae.in

1 Indian National Academy of Engineering, Gurugram, India 